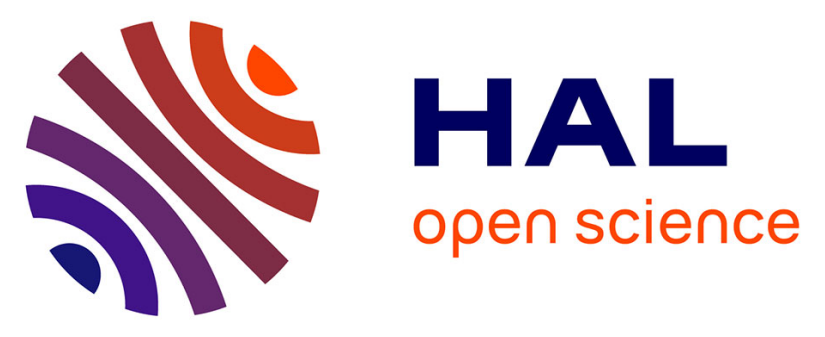

\title{
Patients with stable coronary artery disease and type 2 diabetes but without prior myocardial infarction or stroke and THEMIS-like patients: real-world prevalence and risk of major outcomes from the SNDS French nationwide claims database
}

Patrick Blin, Patrice Darmon, Patrick Henry, Estelle Guiard, Marie Agnes

Bernard, Caroline Dureau-Pournin, Helene Maizi, Florence

Thomas-Delecourt, Regis Lassalle, Cecile Droz-Perroteau, et al.

\section{To cite this version:}

Patrick Blin, Patrice Darmon, Patrick Henry, Estelle Guiard, Marie Agnes Bernard, et al.. Patients with stable coronary artery disease and type 2 diabetes but without prior myocardial infarction or stroke and THEMIS-like patients: real-world prevalence and risk of major outcomes from the SNDS French nationwide claims database. Cardiovascular Diabetology, 2021, 20 (1), pp.229. 10.1186/s12933-021-01416-1 . hal-03524101

\author{
HAL Id: hal-03524101 \\ https://hal.science/hal-03524101
}

Submitted on 13 Jan 2022

HAL is a multi-disciplinary open access archive for the deposit and dissemination of scientific research documents, whether they are published or not. The documents may come from teaching and research institutions in France or abroad, or from public or private research centers.
L'archive ouverte pluridisciplinaire HAL, est destinée au dépôt et à la diffusion de documents scientifiques de niveau recherche, publiés ou non, émanant des établissements d'enseignement et de recherche français ou étrangers, des laboratoires publics ou privés. 


\title{
Patients with stable coronary artery
} disease and type 2 diabetes but without prior myocardial infarction or stroke and THEMIS-like patients: real-world prevalence and risk of major outcomes from the SNDS French nationwide claims database

\author{
Patrick Blin ${ }^{* *}$, Patrice Darmon ${ }^{2,3}$, Patrick Henry ${ }^{4}$, Estelle Guiard ${ }^{1}$, Marie-Agnès Bernard ${ }^{1}$, \\ Caroline Dureau-Pournin ${ }^{1}$, Hélène Maizi ${ }^{1}$, Florence Thomas-Delecourt ${ }^{5}$, Régis Lassalle ${ }^{1}$, \\ Cécile Droz-Perroteau ${ }^{1}$ and Nicholas Moore
}

\begin{abstract}
Aim and hypotheses: The THEMIS randomized trial compared ticagrelor plus aspirin versus placebo plus aspirin for patients with stable coronary artery disease and type 2 diabetes mellitus (CAD-T2DM), and without prior myocardial infarction (MI) or stroke. The aim of the study was to quantify the size of the CAD-T2DM population without prior MI or stroke population in a real-world setting, and more specifically populations with similar THEMIS selection criteria (THEMIS-like and THEMIS-PCI-like populations), as well as their risk of major outcomes in current practice.

Methods: A 2-year follow-up cohort study included all CAD-T2DM without MI/stroke prevalent patients on January 1st, 2014 in the SNDS French nationwide claims database. The THEMIS-like population concerned those $\geq 50$ years of age with similar THEMIS inclusion and exclusion criteria. Prevalence was standardized to the European population. The cumulative incidence function was used to estimate the incidence of clinical outcomes (MI, ischemic stroke, and major bleeding according to the TIMI classification) with death as competing risk, and the Kaplan-Meier estimate for all-cause death and a composite outcome of MI, stroke and all-cause death.
\end{abstract}

Results: From a population of about 50 million adults, the prevalence of CAD-T2DM without MI/stroke, THEMIS-like and THEMIS-PCI-like populations was respectively at 6.04, 1.50 and 0.27 per 1000 adults, with a mean age of 72.7, 72.3 and 70.9 years and less comorbidities and diabetic complications for the THEMIS-like and THEMIS-PCI-like population. The 2-year cumulative incidence was respectively $1.7 \%, 1.3 \%$ and $1.6 \%$ for $\mathrm{MI}, 1.7 \%, 1.5 \%$ and $1.4 \%$ for stroke, 4.8\%, 3.1\% and $2.9 \%$ for major bleeding, $13.6 \%, 9.7 \%$ and $6.8 \%$ for all-cause death, and $16.2 \%, 12.0 \%$ and $9.5 \%$ for the composite outcome.

\footnotetext{
*Correspondence: patrick.blin@u-bordeaux.fr

1 Univ. Bordeaux, INSERM CIC-P 1401, Bordeaux PharmacoEpi, 33000 Bordeaux, France

Full list of author information is available at the end of the article
}

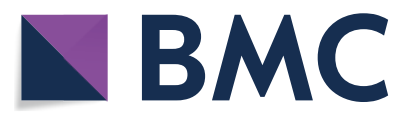

(c) The Author(s) 2021. Open Access This article is licensed under a Creative Commons Attribution 4.0 International License, which permits use, sharing, adaptation, distribution and reproduction in any medium or format, as long as you give appropriate credit to the original author(s) and the source, provide a link to the Creative Commons licence, and indicate if changes were made. The images or other third party material in this article are included in the article's Creative Commons licence, unless indicated otherwise in a credit line to the material. If material is not included in the article's Creative Commons licence and your intended use is not permitted by statutory regulation or exceeds the permitted use, you will need to obtain permission directly from the copyright holder. To view a copy of this licence, visit http://creativecommons.org/licenses/by/4.0/. The Creative Commons Public Domain Dedication waiver (http://creativeco mmons.org/publicdomain/zero/1.0/) applies to the data made available in this article, unless otherwise stated in a credit line to the data. 
Conclusion: THEMIS-like prevalence was estimated at 1.50 per 1,000 adults, representing about a quarter of CADT2DM without MI/stroke patients, and 0.27 per 1000 adults for the THEMIS-PCI-like populations. In current French practice, the median age of both these populations was about 5-6 years older than in the THEMIS trial, with a 2-year incidence of major outcomes between two or four time above the ones of the placebo arm of the THEMIS trial using very close definitions. Registration No. EUPAS27402 (http://www.ENCEPP.eu).

Keywords: Coronary artery disease, Type 2 diabetes mellitus, Prevalence, Myocardial infarction, Stroke, Mortality, Claims database

\section{Introduction}

Coronary artery disease (CAD) is one of the leading causes of mortality and morbidity, affecting almost 49 million people in the European Union, with a cost estimated at around $€ 210$ billion a year $[1,2]$. Type 2 diabetes mellitus (T2DM) is a well-known risk factor for CAD, myocardial infarction (MI) and/or stroke [3-9]. Global estimates of T2DM in adults predict an increase from 415 million persons with T2DM (8.8\%) in 2015 to 642 million (10.4\%) in 2045, confirming the global impact of T2DM, especially in developing countries and impose a large economic burden on health care systems across the world [10]. In France, prevalence of treated T2DM was estimated at $2.6 \%$ in 2000 increasing to $4.4 \%$ in 2009 and $5 \%$ in 2015 , using the nationwide claims database [11, 12]. Patients with both CAD and T2DM, and without MI or stroke history, are at high risk for cardiovascular events $[13,14]$.

In the THEMIS randomized clinical trial (RCT), ticagrelor plus aspirin was compared to a placebo plus aspirin for the prevention of cardiovascular death, MI or stroke in CAD-T2DM patients $\geq 50$ years old without history of MI or stroke, receiving anti-hyperglycaemic drugs for at least 6 months and history of percutaneous coronary intervention (PCI) or coronary artery bypass graft $(\mathrm{CABG})$ or angiographic evidence of $\geq 50 \%$ lumen stenosis of at least one coronary artery [15]. The incidence of ischemic cardiovascular events was lower in the ticagrelor group compared to placebo (7.7\% versus $8.5 \%$, $\mathrm{p}=0.04)$ at 3 years of follow-up, whereas the incidence of major bleeding as defined by the TIMI (Thrombolysis in Myocardial Infarction) criteria was higher $(2.2 \%$ versus $1.0 \%, \mathrm{p}<0.001)$. Furthermore, in the subpopulation of patients with prior $\mathrm{PCI}$, ticagrelor plus aspirin also reduced the 3 -year risk of ischemic events $(7.3 \%$ versus $8.6 \%, p=0.013$ ), which was not the case for patients without prior PCI $(\mathrm{p}=0.76)$, with still more major bleedings in both groups $(2.0 \%$ versus $1.1 \%, \mathrm{p}<0.0001$ and $2.4 \%$ versus $1.0 \%, \mathrm{p}<0.0001$, respectively) [16].

The burden of the corresponding disease is not well known in the overall population. The aim of this study is to estimate the prevalence of the CAD-T2DM population without prior MI or stroke, and more specifically, of a THEMIS-like population, their characteristics and the risk of major outcomes in current practice, which might not be the same as in a highly selected RCT population $[4,17]$.

\section{Methods \\ Design}

The study design was a cohort including all CAD-T2DM prevalent patients on January 1st, 2014 (index date) from the main scheme of the SNDS French nationwide claims database with a 5-year history (2008-2013) and a followup of 2 years (2014-2015).

\section{Setting}

The SNDS links national mandatory public health insurance system claims database to the national hospitaldischarge summaries database system and the national death registry, using a unique national pseudonymised identifier [18]. It currently includes $98.8 \%$ of the French population, more than 66 million persons from birth (or immigration) to death (or emigration), even if a subject changes occupation or retires, and irrespective of socioeconomic status. The main scheme covers $86 \%$ of the French population and is the only one with a history before 2010 used to perform this study [18]. SNDS contains all reimbursed outpatient healthcare expenditures, public and private hospital-discharge summaries with International Classification of Diseases 10th revision (ICD-10) discharge diagnoses, and long-term disease (LTD) registration allowing $100 \%$ reimbursement for expenditure related to the LTD. Date of death is available and causes of death are uploaded gradually but were not available at the time of the study.

\section{Study population}

Three populations were defined and analyzed: CADT2DM without MI-Stroke, THEMIS-like and THEMISPCI-like populations. CAD was defined as patients with at least one hospitalization within the 5-year history or LTD registration with ICD-10 codes I20-25 or coronary artery bypass graft (CABG) for CAD [18], ICD10 I2I-23 for MI [19-21] and ICD-10 codes I63-I64 for ischemic or undefined stroke [22, 23]. T2DM was defined 
as patients with $\geq 3$ non-insulin anti-diabetic dispensing or only long-acting insulin or a large packaging for a 3 -month treatment within the year before index date or at least one hospitalization with ICD-10 codes E11 primary or secondary diagnosis between 2013 and 2014 or LTD registration [24]. THEMIS-like population was defined as CAD-T2DM adult patients $\geq 50$ years without 5-year history of MI or stroke, or renal failure requiring dialysis, cirrhosis or liver cancer, intracranial bleeding, or gastro-intestinal bleeding for the last 6 months, or anticoagulant or P2Y12 inhibitor antiplatelet agent 2 months before or after index date. THEMIS-PCI-like populations as THEMIS-like population with a PCI within the 5-year history but no CABG.

\section{Outcomes}

Outcomes were defined as a hospitalization with a primary diagnosis of the corresponding event. The main outcomes were MI (I21-I23 ICD-10 code), ischemic or unknown stroke (I63-I64 ICD-10 codes), all-cause death, and a composite of MI, stroke (I60-64 ICD-10 codes) and all-cause death, a composite cardiovascular (CV) event. Secondary outcomes were heart failure [25], and major bleeding defined by intracranial bleeding, or other bleeding with transfusion during hospital stay or fatal bleeding $[22,26]$, as a proxy for TIMI major bleeding classification.

\section{Statistical analysis}

Prevalence was estimated for the three study populations and according to sex and three age-classes (18-64, $65-75,>75$ years) in France, and then standardized according to sex and 5-year age-classes for the European population, according to statistics from Eurostat, and the French population according to national statistics from INSEE. The cumulative incidence function was used to estimate primary and secondary clinical outcomes (i.e., MI, ischemic stroke, major bleeding, major organ specific bleeding and heart failure) with death as competing risk, and the Kaplan-Meier estimate for all-cause death and a composite of MI, stroke and all-cause death (composite outcome), for both study populations and for three age-classes $(<65,65-75,>75$ years). Cox proportional hazards model, adjusted on gender, age, PCI and CABG history, was used to assess composite outcome risk factors among major comorbidities before index date (heart failure, atrial fibrillation, cerebrovascular disease, peripheral arterial disease, hypertension, dyslipidemia, chronic renal disease, renal impairment, chronic obstructive pulmonary disease, cancer), 56 SNDS pathology indicators, antidiabetic and CV drug exposure during the 2-year follow-up period as time-dependent covariates (considering that a treatment covers a 30-day period at each dispensing). Statistical analysis was conducted by Bordeaux
PharmacoEpi using SAS ${ }^{\circledR}$ software (SAS Institute, latest current version, North Carolina, USA).

\section{Results}

On January 1st, 2014, 359,540 CAD-T2DM patients were identified within the main scheme of the SNDS database of whom 328,622 were continuously covered by the main scheme for all the study period with complete database history and follow-up. After excluding those with prior MI or stroke, $78.6 \%, 19.6 \%$ and $3.5 \%$ were included in the CAD-T2DM without prior MI or stroke, THEMIS-like and THEMIS-PCI-like population, respectively (Fig. 1).

The general characteristics of CAD-T2DM without $\mathrm{MI} /$ stroke and THEMIS-like population are similar with around two thirds of males, a mean 72 years, $55 \%$ with T2DM history of at least 5 years and $47 \%$ with CAD history of at least 5 years, including $26 \%$ with both T2DM and CAD history of at least 5 years, but comorbidity and diabetic complications were less frequent for the THEMIS-like population, as well as most of main care within the year before index date (Tables 1,2). Compared to the THEMIS-like population, those with PCI were slightly younger with more men and no large difference for disease history, comorbidities, diabetic complications and main care within the year before index date, except for PCI history and three less frequent obstructive sleep apnea syndrome.

The prevalence rate for the European population was 6.04 per 1000 persons for CAD-T2DM without MI/ stroke population, 1.50 for the THEMIS-like population and 0.27 for the THEMIS-PCI-like population, with an estimation of about 2.5 million, 620,000 and 110,000 patients in Europe, respectively (Table 3). The prevalence rate for the French population was very close corresponding to about $317,000,79,000$ and 14,000 patients in France, respectively. The prevalence was higher for men than women in both populations and increased with age. For all patients, as well as according to gender and age classes, the THEMIS-like population represented a quarter of all CAD-T2DM without prior MI or stroke.

The 2-year incidence of primary and secondary outcomes was lower in the THEMIS-like population than for all CAD-T2DM without MI/stroke, but higher than for the THEMIS-PCI-like population (Table 4). For the composite outcome (MI, stroke or all-cause death), it was $16.2 \%$ for CAD-T2DM without MI/stroke, $12.0 \%$ for the THEMIS-like and $9.5 \%$ for the THEMIS-PCI-like with death as the most common event, $13.6 \%, 9.7 \%$ and 6.8 , respectively, and similar and relatively low incidence for MI (1.7\%, 1.3\% and 1,6\%, respectively) and ischemic stroke (1.7, $1.5 \%$ and $1.4 \%$, respectively) (Table 4$)$. While heart failure is more frequent $(9.5 \%, 5.3 \%$ and $4.2 \%$, respectively). For major bleeding, the 2-year incidence 


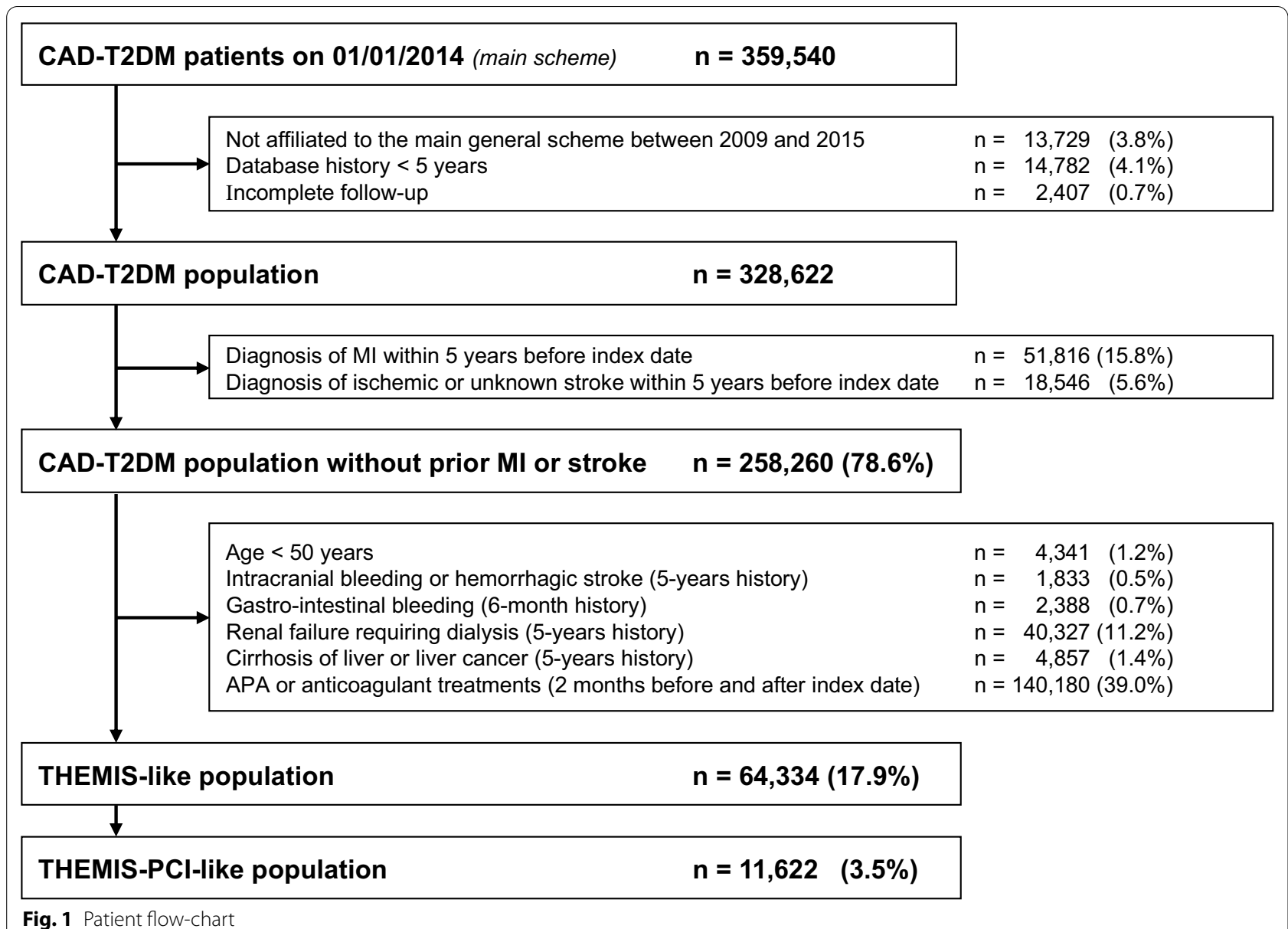

was $4.8 \%, 3.1 \%$ and $2.9 \%$, respectively, including approximatively a quarter of fatal bleeding for the three population $(1.2 \%, 0.7 \%$ and $0.6 \%$, respectively). There was a clear age-related increase in all event incidences, especially marked for heart failure and all-cause death, and except for MI which increased very little for those above 75 years old (Table 4$)$.

In the three populations, the occurrence of the composite outcome (MI, stroke or all-cause death) was associated with male sex, increasing with age, previous history of heart failure, cancer, liver disease, peripheral arterial disease, or mood disorder (Table 5). Patients of the CAD-T2DM without MI/stroke and the THEMISlike population with PCI history presented a lower risk for the composite outcome. During the follow-up, the event rate increased with the use of diuretics and insulin compared with the antidiabetic monotherapy probably from an association with the severity of heart disease and diabetes, respectively (Table 5). The use of antiplatelet agent did not modify the event rates for CAD-T2DM without prior MI or stroke patients, but was associated with a higher risk in the THEMIS-like population, and was probably more a proxy of disease severity as for diuretics and insulin above (Table 5).

\section{Discussion}

The prevalence of the CAD-T2DM without prior MI or stroke, THEMIS-like populations and THEMIS-PCI-like populations, estimated with sex-age standardization for the European adult population, was 6.04, 1.50 and 0.27 per 1000 persons, respectively, increasing with age and with a higher prevalence for men. Thus, the THEMISlike population represented a quarter of all CAD-T2DM without prior MI or stroke, as well as for men, women and each age-class. The 2-year cumulative incidence of main outcome was higher for all CAD-T2DM without $\mathrm{MI} /$ stroke than for the THEMIS-like population, which was itself higher than the THEMIS-PCI-like population except for MI (1.7, 1.3\% and 1.6\%): 1.7\%, $1.5 \%$ and $1.4 \%$ for stroke, $4.8 \%, 3.1 \%$ and $2.9 \%$ for major bleeding, $13.6 \%$, 9.7\% and $6.8 \%$ for all-cause death, $16.2 \%, 12.0 \%$ and $9.5 \%$ for the composite of MI, stroke and all-cause death, respectively. 
Table 1 Patient characteristics at index date for three study populations

\begin{tabular}{|c|c|c|c|}
\hline & $\begin{array}{l}\text { CAD-T2DM without MI/stroke } \\
\text { population }\end{array}$ & THEMIS-like population & $\begin{array}{l}\text { PCI } \\
\text { THEMIS-like } \\
\text { population }\end{array}$ \\
\hline & $n=258,260$ & $n=64,334$ & $n=11,622$ \\
\hline Age in years, mean $( \pm S D)$ & $72.7(10.6)$ & $72.3(10.2)$ & $70.9(9.5)$ \\
\hline Gender male, n (\%) & $176,407(68.3)$ & $42,238(65.7)$ & $8693(74.8)$ \\
\hline \multicolumn{4}{|l|}{ Disease history, n (\%) } \\
\hline T2DM Long Term Disease registration & $199,425(77.2)$ & $50,060(77.8)$ & $9058(77.9)$ \\
\hline CAD Long Term Disease registration & $111,419(43.1)$ & $28,144(43.7)$ & $6327(54.4)$ \\
\hline T2DM history $\geq 5$ years & $142,562(55.2)$ & $35,432(55.1)$ & $6386(54.9)$ \\
\hline CAD history $\geq 5$ years & $121,639(47.1)$ & $29,562(46.0)$ & $5264(45.3)$ \\
\hline Both CAD and T2DM history $\geq 5$ years & $67,040(26.0)$ & $16,346(25.4)$ & $3039(26.1)$ \\
\hline $\mathrm{PCl}$ within the 5-year history & $71,576(27.7)$ & $11657(18.1)$ & $11,622(100)$ \\
\hline CABG within the 5-year history & $1860(0.72)$ & $335(0.5)$ & 0 \\
\hline \multicolumn{4}{|l|}{ Major comorbidities, n (\%) } \\
\hline Hypertension & $204,943(79.4)$ & $48,554(75.5)$ & $8954(77.0)$ \\
\hline Atrial fibrillation & $55,155(21.4)$ & $6647(10.3)$ & $992(8.5)$ \\
\hline Renal impairment & $51,647(20.0)$ & $2943(4.6)$ & $429(3.7)$ \\
\hline Peripheral arterial disease & $49,703(19.2)$ & $7326(11.4)$ & $1462(12.6)$ \\
\hline Dyslipidemia & $49,406(19.1)$ & $10,673(16.6)$ & $2564(22.1)$ \\
\hline Cancer & $47,066(18.2)$ & $10,958(17.0)$ & $1788(15.4)$ \\
\hline Heart failure & $41,744(16.2)$ & $5821(9.0)$ & $932(8.0)$ \\
\hline Chronic obstructive pulmonary disease & $35,558(13.8)$ & $7137(11.1)$ & $1092(9.4)$ \\
\hline Obstructive sleep apnea syndrome, n (\%) & $58,497(22.7)$ & $13,090(20.3)$ & $822(7.1)$ \\
\hline Diabetic complications, n (\%) & $101,419(39.3)$ & $20,301(31.6)$ & 3908 (33.6) \\
\hline Diabetic foot ulcer & $68,149(26.4)$ & $13,506(21.0)$ & $3077(26,5)$ \\
\hline Diabetic nephropathy & $33,126(12.8)$ & $4299(6.7)$ & $645(5.5)$ \\
\hline Diabetic retinopathy & $27,715(10.7)$ & $5400(8.4)$ & $776(6.7)$ \\
\hline Diabetic neuropathy & $25,891(10.0)$ & $4874(7.6)$ & $667(5.7)$ \\
\hline
\end{tabular}

SD, standard deviation; T2DM, type 2 diabetes mellitus; CAD, coronary artery disease, PCI, Percutaneous coronary intervention; CABG, coronary artery bypass graft

The patients included in the THEMIS-like and THEMIS-PCI-like population approximate those included in the THEMIS RCT, with similar inclusion criteria but not exactly the same. However, it was close to criteria that would be applied for therapeutic indication in current practice after such trial. Our results showed that the THEMIS-like population have same mean age, sex-ratio, T2DM and CAD history duration than all CAD-T2DM without prior MI or stroke patients, but a lower rate of comorbidities and diabetic complications, than can be explained by THEMIS exclusion criteria, especially renal failure requiring dialysis and liver cancer or cirrhosis, and probably also anticoagulant treatment or antiplatelet agent prescribed for other comorbidities.

Compared to the patients in the THEMIS RCT placebo arms [15], our THEMIS-like populations was about 6-year older (72.3 vs. 66.0 years) with same sex-ratio and duration of diabetes, a little more peripheral arterial disease $(11.4 \%$ vs. $9.0 \%)$ and diabetes complications (31.6\% vs. $25.3 \%$ ), but less coronary arterial revascularization
$18.6 \%$ within the 5 -year history versus $79.9 \%$ any time with a median of 4.1 years for the most recent. The rate of hypertension and dyslipidemia was also lower $(75.5 \%$ vs. $92.4 \%$ and $16.6 \%$ vs. $87.1 \%$, respectively), but probably related to poor recording, which contrasts with $71.4 \%$ use of statins, and $72.0 \%$ use of ACE inhibitors or angiotensin receptor blockers, $33.1 \%$ use of calcium channel blockers within the year before index date. One patient out of 6 (17.0\%) had cancer, but this was not specified for THEMIS trial. Similar differences were observed for the THEMIS-PCI-like population [16].

In the THEMIS RCT, outcome incidences were also estimated using the Kaplan-Meier estimate but reported after 3 years of follow-up. We estimate the cumulative incidence at 2-years as two-thirds of the 3-year result, considering constant increase during time according to the figures of the publications $[15,16]$. The 2-year cumulative incidence of the composite of MI, any stroke, or all-cause death was $12.0 \%$ for the THEMIS-like population, the double than for the same outcome of the 
Table 2 Main care within the year before index date for the three populations

\begin{tabular}{|c|c|c|c|}
\hline & $\begin{array}{l}\text { CAD-T2DM without MI/stroke } \\
\text { population }\end{array}$ & THEMIS-like population & $\begin{array}{l}\text { PCI } \\
\text { THEMIS-like } \\
\text { population }\end{array}$ \\
\hline & $n=258,260$ & $\mathrm{n}=64,334$ & $n=11,622$ \\
\hline General practitioner visit number, mean ( \pm SD) & $10.2(7.1)$ & $9.5(6.8)$ & $9.5(6.6)$ \\
\hline Cardiologist visit number, mean $( \pm S D)$ & $2.3(2.8)$ & $2.0(2.3)$ & $2.1(2.4)$ \\
\hline Other specialist visit number, mean $( \pm S D)$ & $5.3(7.4)$ & $4.7(6.0)$ & $4.6(6.0)$ \\
\hline \multicolumn{4}{|l|}{ At least one } \\
\hline HbA1c test, n (\%) & $22,1237(85.7)$ & $52,830(82.1)$ & $9666(83.2)$ \\
\hline Hospitalization, n (\%) & $141,149(54.7)$ & $30,215(47.0)$ & $4963(42.7)$ \\
\hline $\mathrm{PCl}, \mathrm{n}(\%)$ & $24,413(9.5)$ & $1429(2.2)$ & $1328(11.4)$ \\
\hline Antidiabetic drug, n (\%) & $227,959(88.3)$ & $54,769(85.1)$ & $10,037(86.4)$ \\
\hline CV drug, n (\%) & $244,660(94.7)$ & $58,550(91.0)$ & $10,697(92.0)$ \\
\hline ASA, n (\%) & $164,045(63.5)$ & $45,829(71.2)$ & $8566(73.7)$ \\
\hline P2Y12i antiplatelet agent, $n$ (\%) & $102,843(39.8)$ & $7372(11.5)$ & $1703(14.7)$ \\
\hline Anticoagulant treatment, $\mathrm{n}(\%)$ & $62,371(24.2)$ & $6273(9.8)$ & $1182(10.2)$ \\
\hline Other CV drugs, n (\%) & $2429,64(94.1)$ & $58,034(90.2)$ & $10,598(91.2)$ \\
\hline Statins & $200,790(77.7)$ & $45,935(71.4)$ & $8445(72.7)$ \\
\hline ACEI or ARB & $199,125(77.1)$ & $46,335(72.0)$ & $8467(72.9)$ \\
\hline Beta blockers & $172,165(66.7)$ & $38,290(59.5)$ & $7157(61.6)$ \\
\hline Diuretics & $108,141(41.9)$ & $22,106(34.4)$ & $4087(35.2)$ \\
\hline Calcium channel blockers & $94,237(36.5)$ & $21,280(33.1)$ & $3907(33.6)$ \\
\hline Organic nitrates & $55,079(21.3)$ & $10,552(16.4)$ & $2043(17.6)$ \\
\hline Other lipid modifying agents than statins & $34,418(13.3)$ & $7900(12.3)$ & $1484(12.8)$ \\
\hline Other vasodilators used in cardiac diseases & $27,003(10.5)$ & $5431(8.4)$ & $1029(8.9)$ \\
\hline
\end{tabular}

SD: Standard Deviation; T2DM: type 2 diabetes Mellitus; CAD: Coronary artery disease; PCl: Percutaneous Coronary Intervention; CABG: coronary artery bypass graft

placebo arm of the THEMIS RCT (first Exploratory outcomes). The difference is related to all-cause death with a three times higher 2-year cumulative incidence $(9.7 \%$ vs. $3.2 \%$ ), whereas this incidence was closer for ischemic stroke $(1.5 \%$ vs. $1.2 \%)$ and lower for MI (1.3\% vs. $2.2 \%)$. Similar differences were observed for the THEMISPCI-like population with about 5 years difference (70.9 vs. 66.0 years) [16]. The main outcome of THEMIS RCT unfortunately, could not be estimated in our study because of the unavailability of cardiovascular mortality. However, the non-cardiovascular death added only $20 \%$ more events between the primary outcome in the placebo group (7.6\%) and the explonary outcome "Death from any cause, myocardial infarction, or stroke" (9.2\%)". The 6-year difference of age between the two studies could explained a part of the death difference, but a significant proportion should correspond to patient selection in RCT, as described by P.G. Steg with the same ratio of 1 to 3 [17]. For major bleeding, the 2-year incidence is also much higher, about 4 times higher, $3.1 \%$ compared to $0.7 \%$ at 2 years of follow-up (1.0 at 3 years).

The major bleeding TIMI classification includes intracranial bleeding, fatal bleeding, and hemorrhage associated with a drop in hemoglobin of $\geq 5 \mathrm{~g} / \mathrm{dL}$ or a $\geq 15 \%$.
Since no lab test result was available in the SNDS database, for this last criterion we used the proxy of hospitalization with bleeding main diagnosis and transfusion during hospital stay, considering that such drop of hemoglobin is an indication for a transfusion and few transfusions should be prescribed for a bleeding with a lower hemoglobin decrease. The large difference of bleeding could be partially linked to other drugs used in real-life setting. If we excluded patients who took P2Y12 inhibitor antiplatelet agents or anticoagulants 2 months before or after index date, $11.5 \%$ of included patients used P2Y12 inhibitor antiplatelet before, and then several patients started P2Y12 inhibitor antiplatelet agent or anticoagulant during the follow-up, while patients treatment was not authorized in the THEMIS RCT. Whatever, we had found similar distortion between patients included in the PEGASUS-TIMI 54 trial and a similar real-life population, in which higher all-cause bleeding rates and death were also found in real-life than in the clinical trial [4].

The SNDS is a national healthcare claims database linked to the national hospital discharge summaries database that covers about $99 \%$ of the French population. It provides a unique opportunity to identify all CAD-T2DM patients, with exhaustive information about reimbursed 
Table 3 Prevalence the three study populations on January 2014 for the European and French adult populations

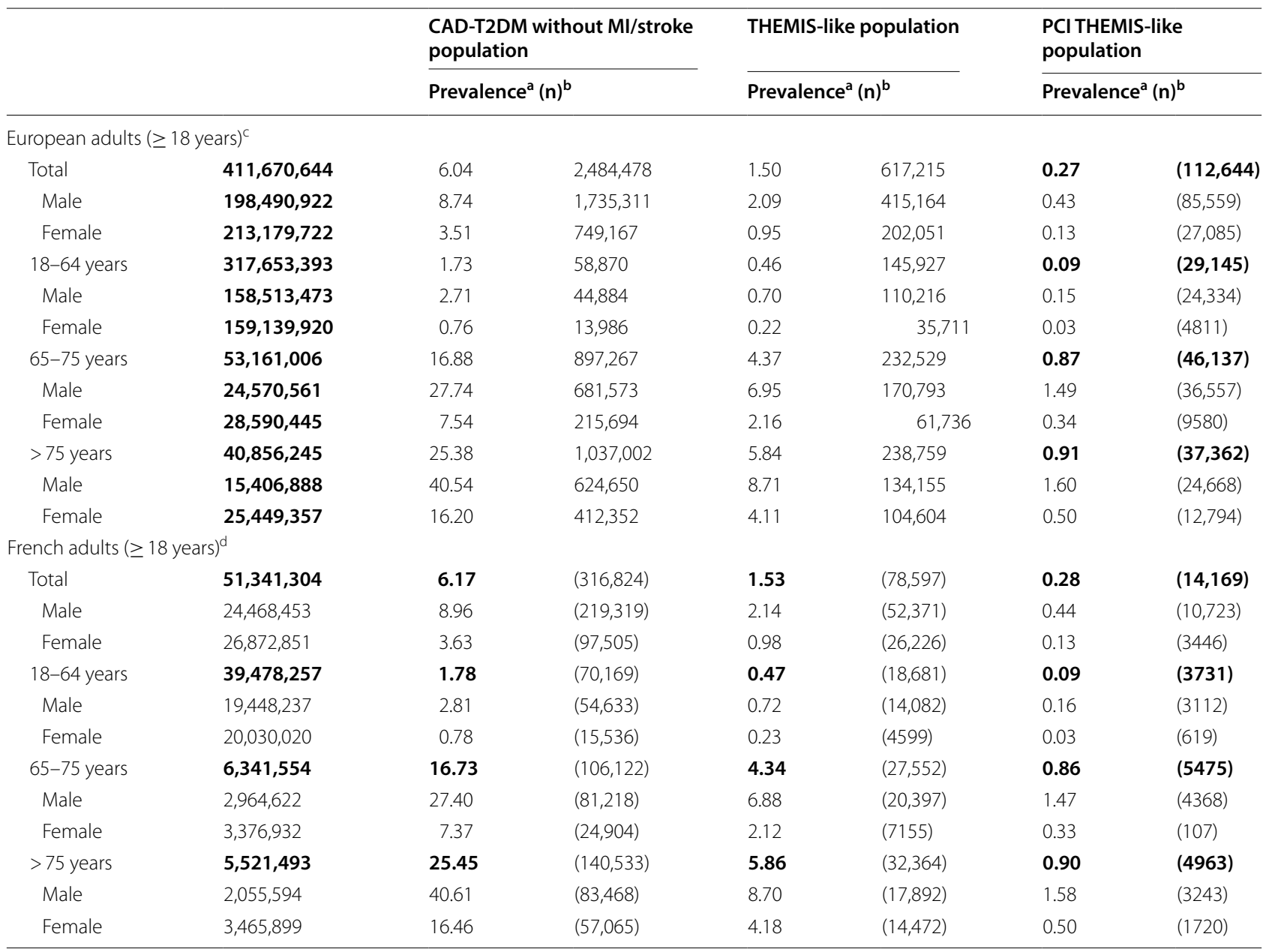

Bold value indicates the size of the cooresponding EU population, i.e. 411.670644 Millions adults in EU

T2DM, type 2 diabetes mellitus; CAD, coronary artery disease

a rate for 1000 adults

${ }^{b} \mathrm{n}=$ estimated number of patients per 1000 adults

' Standardized from Eurostat Population

d Standardized from INSEE Population

treatments out of hospital and use of reimbursed healthcare resources, as well as all hospitalizations. Furthermore, patient records from an existing database are not impacted by the study. The SNDS has already been used to study the type of patients in this study, including for secondary prevention post MI $[15,20]$, or to describe long-term patient outcomes after MI [5].

The main limitation of this claims and hospitalization database is that it was built for administrative and reimbursement purposes with little clinical data and no biological results, including severity or stage of the disease or some risk factors such as diet, environmental exposure, obesity, alcohol, family history, smoking status, and no information about drug adherence, though the full history of drug dispensing may be consistent with adherence, even though medicines that are prescribed are not always taken. This is common in all studies of drug utilization and effects, even with direct access to the patients. The results of lab tests can often be inferred by subsequent medical prescriptions or tests (e.g., measure of transaminases followed by hospital admission for hepatic injury).

Since all patients identified are extracted from a national database, there is no study selection bias, nor attrition bias; patients are included in the database from birth or immigration to death or emigration, irrespective of employer, income, age or social status [18]. Since deaths are recorded in the database using the national death registry, there is no 


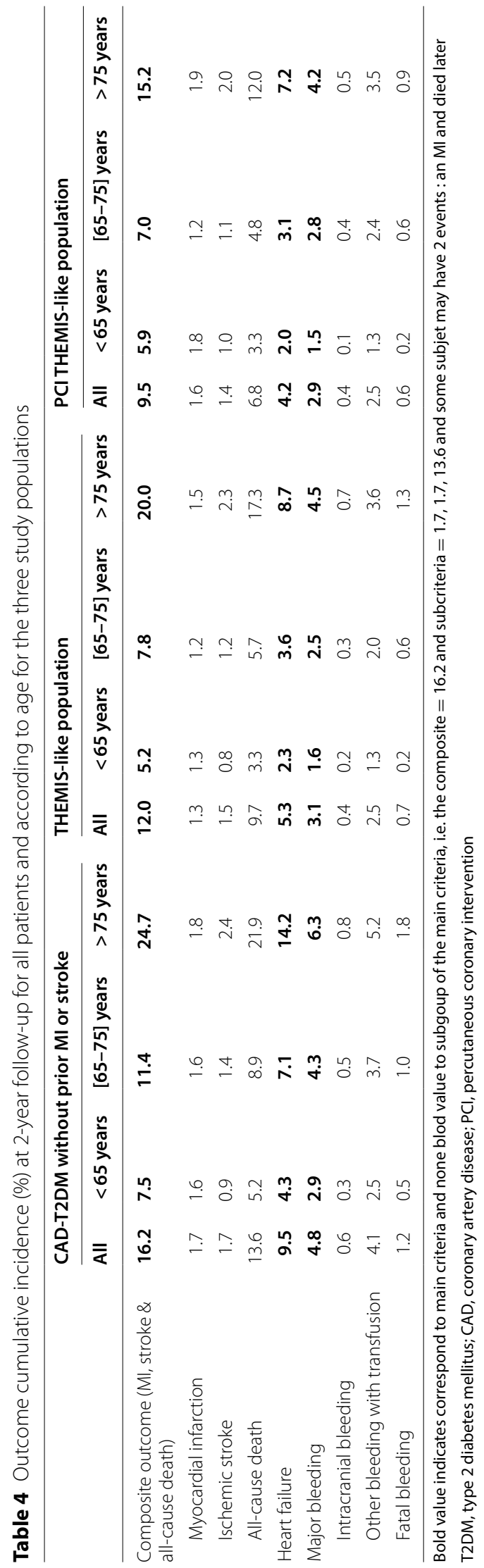


Table 5 Factors Associated with the composite outcome in the three study populations multivariate Cox proportional hazards risk model, selection threshold $\mathrm{HR} \geq 1.20$ or $\mathrm{HR} \leq 0.80$, adjusted on $\mathrm{PCl}$ and $\mathrm{CABG}$ 5-year history)

\begin{tabular}{|c|c|c|c|c|c|c|c|c|c|}
\hline & \multicolumn{3}{|c|}{$\begin{array}{l}\text { CAD-T2DM population without } \\
\text { prior MI or stroke } n=258,260\end{array}$} & \multicolumn{3}{|c|}{$\begin{array}{l}\text { THEMIS-like population } \\
\mathrm{n}=64,334\end{array}$} & \multicolumn{3}{|c|}{$\begin{array}{l}\text { PCI THEMIS-like population } \\
n=11,622\end{array}$} \\
\hline & No & Yes & $\mathrm{HR}[95 \% \mathrm{Cl}]$ & No & Yes & $\mathrm{HR}[95 \% \mathrm{Cl}]$ & No & Yes & $\mathrm{HR}[95 \% \mathrm{Cl}]$ \\
\hline Male ${ }^{a}$ & 148,849 & 27,558 & $1.25[1.22-1.27]$ & 37,396 & 4842 & $1.31[1.25-1.38]$ & 7902 & 791 & 1.14 [0.99-1.31] \\
\hline \multicolumn{10}{|l|}{ Age (in years) } \\
\hline$<55$ & 11,412 & 712 & 1.00 & 2334 & 102 & 1.00 & 460 & 22 & 1.00 \\
\hline $55-59$ & 15,739 & 1210 & 1.18 [1.08-1.29] & 4757 & 225 & $1.04[0.82-1.31]$ & 908 & 45 & 0.98 [0.59-1.63] \\
\hline $60-64$ & 27,295 & 2502 & $1.37[1.26-1.49]$ & 7794 & 483 & 1.34 [1.08-1.66] & 1561 & 117 & $1.42[0.90-2.23]$ \\
\hline $65-69$ & 37,571 & 4244 & $1.64[1.51-1.77]$ & 10,421 & 758 & $1.53[1.24-1.88]$ & 2089 & 133 & $1.19[0.76-1.87]$ \\
\hline $70-74$ & 34,402 & 4804 & $1.95[1.80-2.11]$ & 9143 & 857 & $1.92[1.56-2.36]$ & 1818 & 151 & $1.52[0.97-2.37]$ \\
\hline $75-79$ & 35,768 & 6698 & $2.49[2.30-2.69]$ & 8946 & 1164 & 2.55 [2.09-3.13] & 1677 & 198 & $2.00[1.29-3.12]$ \\
\hline $80-84$ & 31,106 & 8954 & $3.51[3.25-3.79]$ & 7438 & 1536 & 3.78 [3.09-4.62] & 1267 & 204 & $2.54[1.63-3.95]$ \\
\hline $85-89$ & 16,767 & 7687 & $5.07[4.69-5.48]$ & 4066 & 1453 & $5.98[4.88-7.31]$ & 577 & 165 & $4.13[2.64-6.47]$ \\
\hline$\geq 90$ & 6373 & 5016 & 7.74 [7.15-8.38] & 1713 & 1144 & 9.88 [8.06-12.1] & 166 & 64 & $5.10[3.12-8.32]$ \\
\hline $\mathrm{PCl}$ within the 5-year history & 62,072 & 9504 & $0.88[0.86-0.90]$ & 10,555 & 1102 & $0.86[0.81-0.92]$ & & 11,622 & - \\
\hline CABG within the 5-year history & 1544 & 316 & $0.95[0.85-1.06]$ & 304 & 31 & $0.73[0.51-1.04]$ & & 0 & - \\
\hline \multicolumn{10}{|l|}{ Within the 1-year history } \\
\hline Heart failure ${ }^{b}$ & 15,240 & 7783 & $1.77[1.73-1.82]$ & 2278 & 892 & $1.79[1.67-1.92]$ & 316 & 105 & $2.05[1.67-2.52]$ \\
\hline Cancer $^{\mathrm{b}}$ & 26,547 & 9521 & $1.67[1.63-1.71]$ & 6777 & 1728 & $1.70[1.61-1.79]$ & 1166 & 249 & $1.84[1.59-2.12]$ \\
\hline Liver diseases ${ }^{b, c}$ & 5176 & 1882 & $1.80[1.72-1.89]$ & 580 & 82 & $1.16[0.93-1.44]$ & 78 & 14 & $1.64[0.96-2.78]$ \\
\hline Peripheral arterial disease ${ }^{b}$ & 20,657 & 6996 & $1.56[1.52-1.61]$ & 2957 & 799 & $1.72[1.59-1.85]$ & 561 & 149 & $2.21[1.85-2.63]$ \\
\hline Neurotic and mood disorders ${ }^{b}$ & 11,996 & 3377 & $1.29[1.25-1.34]$ & 3221 & 660 & $1.33[1.23-1.45]$ & 393 & 66 & $1.47[1.14-1.89]$ \\
\hline \multicolumn{10}{|l|}{ Within the 2-year follow-up } \\
\hline Diuretics $^{d}$ & & & $1.49[1.46-1.52]$ & & & $1.44[1.37-1.51]$ & & & $1.62[1.42-1.85]$ \\
\hline Antiplatelet agent ${ }^{d}$ & & & $1.03[1.01-1.06]$ & & & $1.29[1.13-1.46]$ & & & $1.24[0.96-1.60]$ \\
\hline \multicolumn{10}{|l|}{ Antidiabetic treatment ${ }^{d}$} \\
\hline Monotherapy & & & 1.00 & & & 1.00 & & & 1.00 \\
\hline No antidiabetic treatment & & & $0.72[0.69-0.75]$ & & & $0.72[0.65-0.80]$ & & & $0.82[0.60-1.11]$ \\
\hline Bitherapy & & & $0.69[0.65-0.72]$ & & & $0.70[0.63-0.79]$ & & & $0.80[0.57-1.13]$ \\
\hline Tritherapy or more & & & $0.65[0.60-0.70]$ & & & $0.67[0.56-0.79]$ & & & $0.73[0.45-1.17]$ \\
\hline Insulin & & & $1.27[1.21-1.32]$ & & & $1.20[1.08-1.34]$ & & & 1.41 [1.03-1.93] \\
\hline
\end{tabular}

$\mathrm{PCl}$, percutaneous coronary intervention; $\mathrm{CABG}$, coronary artery bypass graft

${ }^{a}$ Reference is female

${ }^{b}$ Reference is non-presence of variable

c Excluding chronic viral hepatitis/cystic fibrosis

${ }^{\mathrm{d}}$ Time dependent variables during follow-up

information bias for this outcome. Causes of death were not available at the time of the study in the SNDS, and the primary outcome of THEMIS RCT cannot be estimated in our study, but we used the THEMIS exploratory outcome of MI, any stroke and death for any cause for comparison between both studies. The ICD-10 coding of hospital discharge summaries is regularly audited by the national health insurance system and there is cross-validation of coding between hospitals. In addition, a number of diagnostic codes and strategies such as for MI, heart failure or stroke have been verified with positive predictive values over 90\%, improving over time [27]. The same outcomes have been used in previous studies in the same database $[4,20,22,26]$. All information in the database is fully independent from the study and there is no reason that any potential miscoding will be different between drugs or populations. Some T2DM patients could be misclassified as type 1 because of insulin therapy. To prevent this classification bias, a 5 -year history period was used to investigate prior treatment sequences with sufficient delay to select appropriate T2DM patients. 


\section{Conclusion}

The THEMIS-like population European prevalence was estimated at 1.50 per 1000 adults, representing about a quarter of CAD-T2DM without $\mathrm{MI}$ /stroke patients, in current French practice, with similar general characteristics and less comorbidities, and 0.27 per 1000 adults for the THEMIS-PCI-like populations. The median age of the THEMIS-like and THEMIS-PCI-like populations was about 5-6 years older than in the THEMIS trial, and the 2 -year incidence of major outcomes was well above compared to the placebo arm of the THEMIS trial using very close definitions, about double for the composite outcome, triple for deaths and quadruple for major bleedings than those of the placebo arm of THEMIS RCT. Such lower risk of patients in clinical trials than in real-life is a common observation, and justifies regular verification of drug performances in real-life and the external validity of clinical trials to real-life use of the medications.

\begin{abstract}
Abbreviations
CAD-T2DM: Coronary artery disease; CABG: Coronary artery bypass graft; CV: Cardio vascular; ICD-10: International classification of diseases 10th revision; INSEE: Institut National de la Statistique et des Etudes Economiques; LTD: Long-term disease; MI: Myocardial infarction; PCl: Percutaneous coronary intervention; RCT: Randomized clinical trial; SNDS: Système National des Données de Santé; T2DM: Type 2 diabetes mellitus; TIMI: Thrombolysis in myocardial infarction.
\end{abstract}

\section{Acknowledgements}

Not applicable.

\begin{abstract}
Authors' contributions
PB, PD, PH, EG, CaDP, HM, FTD, CeDP and NM contributed in designing and supervising the study. RL and MAB performed the analyses. All authors discussed the results. PB, EG, CDP, HM and NM wrote the manuscript in consultation with $P D, P H, M A B, R L$ and FTD. All authors read and approved the final manuscript.
\end{abstract}

\section{Funding}

This study was funded by an unrestricted Grant from AstraZeneca through a contract with University of Bordeaux and ADERA, according to the European Network of Centres for Pharmacoepidemiology and Pharmacovigilance code of conduct (http://www.ENCEPP.eu).

\section{Availability of data and materials}

According to the French law, it is forbidden to share individual data from a SNDS data extraction. However, any researcher from a European entity can submit a file to the Health Data Hub (https://www.health-data-hub.fr, new name for the National Institute of Health Data cited above) to have access to the same SNDS data extraction.

\section{Declarations}

\section{Ethics approval and consent to participate}

The study received approval from the National Institute of Health Data (Institut National des Données de Santé-INDS) on July 18th, 2018 and then authorization from French data protection authority (Commission Nationale de I'Informatique et des Libertés-CNIL) on September 17th, 2018. SNDS is a pseudonymized database and no individual patient consent was required. This study complied with all regulations including GDPR and it was registered in the European database of post-approval studies (www.Encepp.eu) as EUPAS27402.

\section{Consent for publication}

All authors give their consent for the publication of information contained in this article to be published in Cardiovascular Diabetology.

\section{Competing interests}

None of the authors benefited personally from this funding, except some of their salary during the study period, and fees for PD and PH for their participation to the scientific committee of the study.

\section{Author details}

${ }^{1}$ Univ. Bordeaux, INSERM CIC-P 1401, Bordeaux PharmacoEpi, 33000 Bordeaux, France. ${ }^{2}$ Hospital La Conception, Marseille, France. ${ }^{3}$ Aix-Marseille University, INSERM, INRA, C2VN, Marseille, France. ${ }^{4}$ Hospital Lariboisiere, Paris, France.

${ }^{5}$ AstraZeneca, Courbevoie, France.

Received: 9 August 2021 Accepted: 12 November 2021

Published online: 25 November 2021

\section{References}

1. Timmis A, Townsend N, Gale C, Grobbee R, Maniadakis N, Flather M, et al. European society of cardiology: cardiovascular disease statistics 2017. Eur Heart J. 2018;39(7):508-79.

2. Timmis A, Townsend N, Gale CP, Torbica A, Lettino M, Petersen SE, et al. European society of cardiology: cardiovascular disease statistics 2019. Eur Heart J. 2020:41(1):12-85.

3. Beckman JA, Paneni F, Cosentino F, Creager MA. Diabetes and vascular disease: pathophysiology, clinical consequences, and medical therapy: part II. Eur Heart J. 2013;34(31):2444-52.

4. Blin P, Dureau-Pournin C, Lassalle R, Jove J, Thomas-Delecourt F, DrozPerroteau $\mathrm{C}$, et al. Outcomes in patients after myocardial infarction similar to those of the PEGASUS-TIMI 54 trial: a cohort study in the French national claims database. Br J Clin Pharmacol. 2017;83(9):2056-65.

5. Cosentino F, Grant PJ, Aboyans V, Bailey CJ, Ceriello A, Delgado V, et al. 2019 ESC guidelines on diabetes, pre-diabetes, and cardiovascular diseases developed in collaboration with the EASD. Eur Heart J. 2020;41(2):255-323.

6. Emerging Risk Factors C, Di Angelantonio E, Kaptoge S, Wormser D, Willeit P, Butterworth AS, et al. Association of cardiometabolic multimorbidity with mortality. JAMA. 2015;314(1):52-60.

7. Seshasai SRK, Kaptoge S, Thompson A, Di Angelantonio E, Gao P, Sarwar $\mathrm{N}$, et al. Diabetes mellitus, fasting glucose, and risk of cause-specific death. N Engl J Med. 2011;364(9):829-41.

8. Rawshani A, Rawshani A, Franzen S, Eliasson B, Svensson AM, Miftaraj M, et al. Mortality and cardiovascular disease in type 1 and type 2 diabetes. N Engl J Med. 2017;376(15):1407-18.

9. Ryden L, Grant PJ, Anker SD, Berne C, Cosentino F, Danchin N, et al. ESC guidelines on diabetes, pre-diabetes, and cardiovascular diseases developed in collaboration with the EASD: the task force on diabetes, pre-diabetes, and cardiovascular diseases of the European society of cardiology (ESC) and developed in collaboration with the European association for the study of diabetes (EASD). Eur Heart J. 2013;34(39):3035-87.

10. Ogurtsova K, da Rocha Fernandes JD, Huang Y, Linnenkamp U, Guariguata L, Cho NH, et al. IDF diabetes atlas: global estimates for the prevalence of diabetes for 2015 and 2040. Diabetes Res Clin Pract. 2017;128:40-50.

11. Mandereau-Bruno LF-ES. Prevalence of pharmacologically-treated diabetes (all types) in france in 2015. Territorial and socio-economic disparities. Bulletin Epidemiologique Hebdomadaire. 2015;2017(27-28):586-91.

12. BrP RP, Weill $A$, Simon $D$, Tuppin $P$, Ricordeau $P$, Allemand H. Diabète traité: quelles évolutions entre 2000 et 2009 en France? Bulletin Epidemiologique Hebdomadaire. 2000;2010(42-43):425-31.

13. Haffner SM, Lehto S, Ronnemaa T, Pyorala K, Laakso M. Mortality from coronary heart disease in subjects with type 2 diabetes and in nondiabetic subjects with and without prior myocardial infarction. N Engl J Med. 1998;339(4):229-34.

14. Krempf M, Parhofer KG, Steg PG, Bhatt DL, Ohman EM, Rother J, et al. Cardiovascular event rates in diabetic and nondiabetic individuals with and without established atherothrombosis (from the REduction of 
Atherothrombosis for Continued Health [REACH] Registry). Am J Cardiol. 2010;105(5):667-71.

15. Steg PG, Bhatt DL, Simon T, Fox K, Mehta SR, Harrington RA, et al. Ticagrelor in patients with stable coronary disease and diabetes. N Engl J Med. 2019;381(14):1309-20

16. Bhatt DL, Steg PG, Mehta SR, Leiter LA, Simon T, Fox K, et al. Ticagrelor in patients with diabetes and stable coronary artery disease with a history of previous percutaneous coronary intervention (THEMIS-PCI): a phase 3 , placebo-controlled, randomised trial. Lancet. 2019;394(10204):1169-80.

17. Steg PG, Lopez-Sendon J, Lopez de Sa E, Goodman SG, Gore JM, Anderson FA Jr, et al. External validity of clinical trials in acute myocardial infarction. Arch Intern Med. 2007;167(1):68-73.

18. Bezin J, Duong M, Lassalle R, Droz C, Pariente A, Blin P, et al. The national healthcare system claims databases in France, SNIIRAM and EGB: powerful tools for pharmacoepidemiology. Pharmacoepidemiol Drug Saf. 2017:26(8):954-62.

19. Bezin J, Girodet PO, Rambelomanana S, Touya M, Ferreira P, Gilleron V, et al. Choice of ICD-10 codes for the identification of acute coronary syndrome in the French hospitalization database. Fundam Clin Pharmacol. 2015;29(6):586-91.

20. Blin P, Dureau-Pournin C, Benichou J, Bonello L, Dallongeville J, Danchin $\mathrm{N}$, et al. Secondary prevention of acute coronary events with antiplatelet agents (SPACE-AA): one-year real-world effectiveness and safety cohort study in the French nationwide claims database. Atherosclerosis. 2019;281:98-106.

21. Blin P, Dureau-Pournin C, Jove J, Lassalle R, Droz C, Moore N. Secondary prevention of acute coronary syndrome with antiplatelet agents in real life: a high-dimensional propensity score matched cohort study in the French National claims database. MethodsX. 2020;7: 100796.
22. Blin P, Fauchier L, Dureau-Pournin C, Sacher F, Dallongeville J, Bernard MA, et al. Effectiveness and safety of rivaroxaban 15 or $20 \mathrm{mg}$ versus vitamin $\mathrm{K}$ antagonists in nonvalvular atrial fibrillation. Stroke. 2019;50(9):2469-76.

23. Giroud M, Hommel M, Benzenine E, Fauconnier J, Bejot Y, Quantin C, et al. Positive predictive value of french hospitalization discharge codes for stroke and transient ischemic attack. Eur Neurol. 2015;74(1-2):92-9.

24. Fuentes S, Cosson E, Mandereau-Bruno L, Fagot-Campagna A, Bernillon $\mathrm{P}, \mathrm{Goldberg} \mathrm{M}$, et al. Identifying diabetes cases in health administrative databases: a validation study based on a large French cohort. Int J Public Health. 2019;64(3):441-50.

25. Bosco-Levy P, Duret S, Picard F, Dos Santos P, Puymirat E, Gilleron V, et al. Diagnostic accuracy of the international classification of diseases, tenth revision, codes of heart failure in an administrative database. Pharmacoepidemiol Drug Saf. 2019;28(2):194-200.

26. Blin P, Dureau-Pournin C, Cottin Y, Benichou J, Mismetti P, Abouelfath A, et al. Comparative effectiveness and safety of standard or reduced dose dabigatran vs. rivaroxaban in nonvalvular atrial fibrillation. Clin Pharmacol Ther. 2019;105(6):1439-55.

27. Haviari S, Chollet F, Polazzi S, Payet C, Beauveil A, Colin C, et al. Effect of data validation audit on hospital mortality ranking and pay for performance. BMJ Qual Saf. 2019;28(6):459-67.

\section{Publisher's Note}

Springer Nature remains neutral with regard to jurisdictional claims in published maps and institutional affiliations.
Ready to submit your research? Choose BMC and benefit from:

- fast, convenient online submission

- thorough peer review by experienced researchers in your field

- rapid publication on acceptance

- support for research data, including large and complex data types

- gold Open Access which fosters wider collaboration and increased citations

- maximum visibility for your research: over 100M website views per year

At BMC, research is always in progress.

Learn more biomedcentral.com/submissions 